\title{
NON-COMMUNICABLE DISEASES IN THE ASIA-PACIFIC REGION: PREVALENCE, RISK FACTORS AND COMMUNITY-BASED PREVENTION
}

\author{
WAH-YUN LOW, YEW-KONG LEE, and ALEXANDER LOURDES SAMY \\ University of Malaya, Kuala Lumpur, Malaysia \\ Faculty of Medicine
}

\begin{abstract}
Non-communicable diseases (NCDs) lead to substantial mortality and morbidity worldwide. The most common NCDs are cardiovascular diseases (CVD), diabetes, cancer and chronic respiratory diseases. With the rapid increase in NCD-related deaths in Asia Pacific countries, NCDs are now the major cause of deaths and disease burden in the region. NCDs hamper achievement of the Millennium Development Goals (MDG). People in the low socio-economic group are most affected by NCDs as they have poor access to policies, legislations, regulations and healthcare services meant to combat NCDs. This results in loss of productivity by a decreasing labor force with implications at the macroeconomic level. The 3 major NCDs in the Asia Pacific region are CVDs, cancer and diabetes due to the increasing loss of disability adjusted life years (DALYs). The 4 major behavioral risk factors for NCDs are: tobacco use, alcohol consumption, inadequate physical activity and unhealthy diet. The underlying risk factors are urbanization, globalization, sedentary lifestyle, obesity and hypertension. Strategies to combat NCDs in the Asia Pacific region are as follows: population-based dietary salt reduction, health education, psychological interventions, i.e., cognitive behavioral therapy and motivational-interviewing, taxation and bans on tobacco-related advertisements, implementing smoke-free zones and surveillance by the World Health Organization. Control measures must focus on prevention and strengthening inter-sectorial collaboration.
\end{abstract}

Key words:

Non-communicable diseases (NCDs), Urbanization, Hypertension, Obesity, Community-based prevention,

Inter-sectorial collaboration

\section{INTRODUCTION}

Non-communicable diseases (NCDs) are the pivotal cause of disease burden and mortality in the Asia Pacific region, claiming $55 \%$ of total life in the South East Asia region each year and $75 \%$ in the Western Pacific region [1,2]. The Asia Pacific region is experiencing a rapid increase in NCD-related deaths; the World Health Organization estimates that the highest worldwide increment in total mortality in a 10-year time frame (2005-2015) will be observed in the South-East Asia and Western Pacific regions with 21\% increase in the South-East Asia region [3] and 12.3 million deaths in the Western Pacific region [2]. This increase in NCDs presents a major barrier to global development, specifically to the achievement of the Millennium Development Goals [4] in low-and-middle income countries.

This paper was presented at the 6th ICOH International Conference on Work Environment and Cardiovascular Diseases; 2013 Mar 27-30; Tokyo, Japan. Received: May 9, 2014. Accepted: September 3, 2014.

Corresponding author: W.-Y. Low, Faculty of Medicine, University of Malaya, 50603 Kuala Lumpur, Malaysia (e-mail: lowwy@um.edu.my). 


\section{THE BIG THREE IN THE ASIA PACIFIC REGION: CARDIOVASCULAR DISEASES (CVDS), DIABETES, CANCER}

Cardiovascular diseases, diabetes and cancer constitute the Asia Pacific region's biggest NCD challenges. The total number of disability adjusted life years (DALYs) lost due to these 3 diseases is significantly higher compared to other NCDs. For example, between 1990 and 2010, the DALYs due to CVDs, diabetes mellitus and cancer increased by $22.6 \%, 69 \%$ and $27.3 \%$, while it decreased by $2 \%$ due to respiratory diseases [5].

In particular, the Asia Pacific region is severely affected by the burden from CVDs. The total number of DALYs lost to CVDs in this region constituted more than $50 \%$ of the worldwide sum of DALYs lost to CVDs in 2005 [6]. The Maldives had the highest female age-standardized death rate for ischemic heart disease (218 per 100 000), while Fiji had the highest rate for males (304 out of 100 000) [6]. The highest rate for stroke was also reported in the Asia Pacific region - Mongolia recorded the highest female agestandardized death rate for stroke (189 out of 100000 ), while Sri Lanka had the highest rate for males (256 out of 100000$)$ [6].

Similar figures with respect to diabetes in the region are also alarming. Between 2000 and 2010, the Asia Pacific region alone experienced a $57 \%$ increase in the absolute number of people with diabetes, from 84.5 to 132.3 million. Currently, population prevalence rates are as high as $31 \%$ in Nauru, and 10-14\% in French Polynesia, Tuvalu, Tonga, Brunei, Malaysia and Singapore [7]. Combining impaired glucose tolerance (IGT) and diabetes, more than $50 \%$ of the population in Nauru are affected [7]. Most patients with diabetes have poor glycemic control, which contributes to the microvascular and neurological complications of the disease, as well as the progression from pre-diabetes. In China, $40 \%$ of diabetic patients have poor control as measured by glycated hemoglobin (HbA1c > 7.5\%) [8]. Furthermore, a regional study reported that $79 \%$ of patients have $\mathrm{HbA1c}>7 \%$ [9]. Table 1 shows mortality rates for cardiovascular diseases and diabetes in selected countries from the Asia Pacific region in 2008.

Cancer accounts for $13 \%$ of all deaths in the Asia Pacific region. Worldwide, $70 \%$ of all cancer-related deaths occurred in low-and middle- income countries where access to healthcare resources is poor. In 2000 , there were 4.3 million cases resulting in 2.9 million deaths from cancer in the Asia Pacific region, with lung cancer being the most prevalent [10]. Indeed, tobacco use remains the major avoidable risk factor for cancer. This includes tobacco chewing, which is the leading cause of oral cancer. In addition, high

Table 1. Mortality rate due to cardiovascular diseases and diabetes in selected countries in the Asia-Pacific region in 2008 [11]

\begin{tabular}{lcc}
\hline \multirow{2}{*}{ Country } & \multicolumn{2}{c}{ Mortality } \\
& \multicolumn{2}{c}{ (death $\begin{array}{c}\text { (n) } \\
\text { (n) }\end{array}$} \\
\cline { 2 - 3 } Australia & female \\
Bangladesh & 136 & 89 \\
Cambodia & 447 & 388 \\
China & 480 & 339 \\
Fiji & 312 & 260 \\
India & 580 & 328 \\
Indonesia & 386 & 283 \\
Japan & 400 & 300 \\
Malaysia & 118 & 65 \\
Myanmar & 319 & 286 \\
Nauru & 412 & 327 \\
Pakistan & 922 & 473 \\
Papua New Guinea & 455 & 388 \\
Republic of Korea & 460 & 395 \\
Samoa & 168 & 115 \\
Singapore & 477 & 374 \\
Sri Lanka & 171 & 179 \\
Thailand & 385 & 241 \\
Tuvalu & 343 & 280 \\
Viet Nam & 606 & 568 \\
\hline
\end{tabular}


Table 2. Mortality rate due to cancer in selected countries in the Asia Pacific region in 2008 [11]

\begin{tabular}{|c|c|c|}
\hline \multirow[t]{2}{*}{ Country } & \multicolumn{2}{|c|}{$\begin{array}{c}\text { Mortality } \\
\text { (death per } 100000 \text { people) } \\
(\mathrm{n})\end{array}$} \\
\hline & male & female \\
\hline Australia & 141 & 93 \\
\hline Bangladesh & 105 & 107 \\
\hline Cambodia & 145 & 90 \\
\hline China & 182 & 105 \\
\hline Fiji & 106 & 122 \\
\hline India & 79 & 72 \\
\hline Indonesia & 136 & 109 \\
\hline Japan & 150 & 77 \\
\hline Malaysia & 119 & 90 \\
\hline Myanmar & 123 & 115 \\
\hline Nauru & 115 & 191 \\
\hline Pakistan & 95 & 94 \\
\hline Papua New Guinea & 152 & 107 \\
\hline Republic of Korea & 191 & 77 \\
\hline Samoa & 69 & 40 \\
\hline Singapore & 142 & 91 \\
\hline Sri Lanka & 90 & 78 \\
\hline Thailand & 115 & 96 \\
\hline Tuvalu & 107 & 154 \\
\hline Viet Nam & 137 & 94 \\
\hline
\end{tabular}

rates of nasopharyngeal cancer were reported for some parts of China and Southeast Asia, with the main risk factors being smoking and alcohol intake [6]. Table 2 presents mortality rates for cancer in selected countries in the Asia Pacific region.

\section{RISK FACTORS FOR NCDs} IN THE ASIA PACIFIC REGION

Risk factors for NCDs include underlying factors (e.g., social determinants, globalization, urbanization, ageing), behavioral risk factors (e.g., unhealthy diet, tobacco use, sedentary lifestyle) and metabolic/physiological risk factors (e.g., increased blood glucose, increased blood pressure, obesity and raised lipids) [12]. These risk factors combine into a series of critical pathways which result in NCDs such as: diabetes, ischemic heart disease, cancer, stroke and chronic lung diseases [13].

The major underlying risk factor for the rise in NCDs in the Asia Pacific region is the socio-cultural epidemiological transition. As a result of economic development, the region has undergone drastic changes in the lifestyle and nutrition of its population. Thus, an increase in NCDs, including obesity and diabetes, has paralleled the growth of urbanization and globalization in the region. In China, the prevalence rates of diabetes in large provincial capital cities range from a high of $8 \%$ (in the Eastern region) to $4.6 \%$ (the lowest in the Western region) [14].

Behavioral risk factors include tobacco use, alcohol consumption, unhealthy diet and physical inactivity. In fact, the impact of the global tobacco epidemic is the most severe in the Asia Pacific region. Tobacco use is the highest in developing countries (75\% of all worldwide users) with 2.3 million tobacco-related premature deaths annually in the Asia Pacific region [15]. It is the 2nd major cause of all deaths from NCDs and the 4th most common risk factor for the diseases worldwide [2].

For alcohol consumption, the total DALYs lost due to harmful alcohol use was $4.5 \%$, with cancer, CVDs and liver disease comprising a quarter of this burden [16]. In a study conducted in Japan, the prevalence of colorectal cancer attributable to alcohol intake and smoking was $46 \%$. Moreover, consumption of alcohol of $300 \mathrm{~g} /$ week or above contributed to a 3-fold higher risk of colorectal cancer (odds ratio $(\mathrm{OR})=3 ; 95 \%$ confidence interval (CI): 1.8-5.1) [17].

Physical inactivity is the 4th leading risk factor for mortality, accounting for 32.1 million total DALY lost [16]. People who do not have sufficient physical activity have 
a $20-30 \%$ increased risk of mortality compared to those who engage in an exercise regime that lasts at least $30 \mathrm{~min}$ a day [18]. A study on Asian countries via a health surveillance database reported that a quarter of men and a $3 \mathrm{rd}$ of women were physically inactive [18].

As mentioned before, there has also been a major nutritional shift in the traditional Asian and Western Pacific diets with rapid urbanization due to economic prosperity [20]. At the same time, consumption of traditional Asian foods, such as pickles, sa-um or smoked dried meat and dried fish have been implicated with stomach cancer which is quite high in several countries in the region, especially: Iran, Central Asian Republic, China, Korea and Japan [21]. The bacteria Helicobacter pylori, is responsible for this type of cancer and the spread of this specific infection is very well known due to dietary habits.

Looking at obesity as a risk factor, it was projected that in Australia by $2015,75 \%$ of women aged 30 and above will be overweight (body mass index (BMI) > 25) [22], with 50\% of overweight women in the Southeast Asian countries of Malaysia, Thailand, Myanmar and Vietnam [23]. In many countries of the Asia Pacific region, obesity is a rising public health concern directly associated with NCDs, notably, diabetes, hypertension, dyslipidemia and coronary heart disease. In this regard, the Maldives reported the highest prevalence of obesity within the Asia Pacific region, with $60.8 \%$ of males and $65.5 \%$ of females being overweight and obese [24].

Finally, CVDs are attributable to hypertension [25]. This condition is getting prevalent worldwide, not only in the developed nations. One third of deaths in the middle income countries were caused by CVDs due to hypertension [25]. In a study across the Asia Pacific region, compared to normal blood pressure, prehypertension as well as other types of hypertension were clearly associated with an increased risk of CVDs, adjusted for age, sex, cholesterol and smoking [26].

\section{STRATEGIES TO TACKLE THE INCREASE IN NCDs}

The alarming rise in mortality and morbidity due to NCDs in the Asia Pacific region warrants comprehensive multilevel strategies beginning at the individual up to the population level. As low-and middle-income countries face the biggest threat, emphasis needs to be given to cost-effective population-wide prevention and health programs to improve the quality of life. Cost-effective interventions do exist and are effective regardless of the income level of a country. What is needed are high levels of evidencebased planning, commitment, community mobilization and profound focus on a small range of critical actions [12].

One measure to reduce CVDs via preventing hypertension risk is population-based dietary salt reduction. A randomized controlled trial on reducing salt consumption among free-dwelling people in 2 rural villages in north-eastern Japan resulted in a significant decrease in systolic blood pressure in the intervention group; from $127.9 \mathrm{~mm} \mathrm{Hg}$ to $125.2 \mathrm{~mm} \mathrm{Hg}$ (2.7 $\mathrm{mm} \mathrm{Hg}$ decrease; 95\% CI: -4.6 to -0.8) [27]. This action could be augmented by legislating reduced salt in processed and fast foods, which have become popular among people in Asian Pacific countries [28, 29].

Education on blood pressure, cholesterol and weight should be emphasized at school level as it serves as an appropriate place for health promotion and education so as to reduce the risks of CVDs. Advocating people to practice a healthy lifestyle through education (in and out of school) as well as through health promotion campaigns and support groups is deemed necessary. An intervention program conducted in India, namely MARG (Medical education for children / Adolescents for Realistic prevention of obesity and diabetes and for healthy aGeing), resulted in children (aged 8-11 years old) with 15\% improvement in knowledge regarding trans-fatty acid, obesity, diabetes, physical activity and blood pressure. An additional $10 \%$ of the students regarded steaming of food as a healthy cooking method and preferred outdoor games compared to the indoor ones [29]. 
Tackling consumption of tobacco in the Asia Pacific region requires strong policy interventions. Taxation has proven to be an effective way to control tobacco use. An increment of $10 \%$ in cigarette price was shown to reduce cigarette demand by $2-8 \%$ in low-and-middle income countries. Thanks to this measure, youths, minorities and low-income smokers were more likely to use less tobacco [30]. Furthermore, 1/3 of tobacco experimentation among youths occurs due to tobacco advertising, promotion and sponsorship (TAPS). Therefore, comprehensive bans on TAPS need to be implemented in all Asia Pacific countries in order to limit initiation of tobacco consumption [31]. Establishing smoke-free zones has also decreased the probability of tobacco use. A cross-sectional study in Zhejiang, China, has revealed that places with a complete indoor smoking ban were 5 times more likely to be smoke-free compared to the venues without a smoking-ban at the point of survey (OR = 5.39; 95\% CI: 1.92-15.14) [32]. Malaysia has imposed a Smoke-Free Legislation (SFL) throughout the country and smoking is prohibited in all air-conditioned premises. Malacca, a popular state for tourism in the country, has adapted the SFL by introducing smoke-free zones in 5 areas of its capital city since June 2011 [33]. Reduction in tobacco-consumption, particularly smoking, can reduce the risk of mortality due to lung cancer within 5-years from smoking cessation [34]. Surveillance serves as a global strategy in preventing and controlling NCDs and their major risk profiles preceding a disease onset, particularly in developing countries [35]. It also serves as a gateway for low- and middle-income countries to embark on chronic disease surveillance activities [36]. A STEPwise approach [37], comprising 3 steps, has been formulated to document, analyze and disseminate data on the established risk profiles that determine the major disease burden in the WHO member countries. Step 1 concerns behaviors (basic demographic information, alcohol consumption, tobacco use, intake of fruit and vegetables, and physical activity). Step 2 includes physical measurements (weight, height, waist circumference and blood pressure). Step 3 comprises biochemical analyses (fasting blood sugar and total cholesterol). The advantage of this instrument is that it is not limited to monitoring a country's trends in risk factors for NCDs but it can also be used to make cross-country comparisons [38]. On the whole and, particularly in the context of public health, surveillance serves as an important tool in decision-making and monitoring the progress of interventions to control and decrease the emerging epidemics of NCDs.

\section{CONCLUSIONS}

Non-communicable diseases are the leading cause of mortality and morbidity worldwide, especially in the Asia Pacific region. The big three NCDs in the region are cardiovascular diseases, diabetes and cancer. In addition, the prevalence and incidence of these NCDs are rising, particularly in rapidly developing Asia Pacific countries, such as China, India and some ASEAN countries. Sustainable cost-effective and population-wide interventions are deemed useful and practical in the low-andmiddle income countries in the Asia Pacific region, with maximum scalability and transferability to all the people regardless of their socio-economic status. Strategies in combating NCDs are not exhaustive. Programs carried out by national and international efforts, such as STEPs by WHO, could serve a larger population at lower cost in maintaining optimal health through the predominant STEPs program.

Clearly, inter-sectorial collaboration, encompassing both health and relevant non-health sectors, is necessary in combating NCDs in the Asia Pacific region. The goal of inter-sectorial collaboration is to achieve increased awareness on health and health-related matters, and health consequences of policy decisions and organizational practices in different sectors, thereby leading towards healthy public practice and policy across various sectors $[39,40]$. 


\section{REFERENCES}

1. World Health Organization. Action plan for the prevention and control of noncommunicable diseases in South-East Asia, 2013-2020. New Delhi: WHO Regional Office for South-East Asia; 2013.

2. World Health Organization. Noncommunicable diseases in the Western Pacific Region. Manila: WHO Office of the Western Pacific Region; 2012.

3. World Health Organization. Noncommunicable diseases in the South-East Asia Region: Situation and response 2011. New Delhi: WHO Regional Office for South-East Asia; 2011.

4. Beaglehole R, Bonita R, Horton R, Adams C, Alleyne G, Asaria P, et al. Priority actions for the non-communicable disease crisis. Lancet. 2011;377:1438-47, http://dx.doi.org/ 10.1016/S0140-6736(11)60393-0.

5. Hunter DJ, Reddy KS. Noncommunicable diseases. N Engl J Med. 2013;369(14):1336-43, http://dx.doi.org/10.1056/NEJ Mra1109345.

6. World Health Organization. Priority noncommunicable diseases and conditions. WHO Office for Western Pacific Region; 2008 [cited 2014 Feb 28]. Available from: http://www. wpro.who.int/health_research/documents/dhs_hr_health_ in_asia_and_the_pacific_13_chapter_8_priority_noncommunicable_diseases_and_disorders.pdf.

7. International Diabetes Federation. Diabetes Atlas. 3rd ed. Brussels: IDF; 2006.

8. Ling T, Bao CX, Yun $\mathrm{CH}$. The control of fasting plasma glucose and HbA1c multifactor analysis for medical cost in patients with type 2 diabetes mellitus. Chin J Diabetes. 2004;3:205-8.

9. Chuang L-M, Tsai ST, Huang BY, Tai TY. The status of diabetes control in Asia - A cross-sectional survey of 24317 patients with diabetes mellitus in 1998. Diabet Med. 2002;19(12):978-85, http://dx.doi.org/10.1046/j.1464-5491.2002. 00833.x.

10. Parkin DM, Bray F, Ferlay J, Pisani P. Global cancer statistics, 2002. CA Cancer J Clin. 2005;55(2):74-108, http:// dx.doi.org/10.3322/canjclin.55.2.74.
11. World Health Organization. Global health observatory data repository. WHO; 2013 [cited 2014 Mar 28]. Available from: http://apps.who.int/gho/data/node.main.A865?lang=en.

12. World Health Organization. Global status report on noncommunicable diseases 2010. Geneva: WHO; 2011.

13. World Health Organization. Preventing chronic diseases: A vital investment. WHO global report. Geneva: WHO; 2005.

14. Zuo H, Shi Z, Hussain A. Prevalence, trends and risk factors for the diabetes epidemic in China: A systematic review and meta-analysis. Diabetes Res Clin Pract. 2014;104(1):63-72, http://dx.doi.org/10.1016/j.diabres.2014.01.002.

15. Anderson I. Tobacco as a development issue: Latest estimates from WHO. 2012 [cited 2014 Apr 5]. Available from: http://devpolicy.org/tobacco-as-a-development-issue-latestestimates-from-who20120430.

16. World Health Organization. Global health risk: Mortality and burden of disease attributable to selected major risks. Geneva: WHO; 2009.

17. Otani T, Iwasaki M, Yamamoto S, Sobue T, Hanaoka T, Inoue $\mathrm{M}$, et al. Alcohol consumption, smoking, and subsequent risk of colorectal cancer in middle-aged and elderly Japanese men and women Japan public health centerbased prospective study. Cancer Epidemiol Biomarkers Prev. 2003;12(12):1492-500.

18. World Health Organization. Global recommendation on physical activity for health. Geneva: WHO; 2010.

19. Ng N, Hakimi M, van Minh H, Juvekar S, Razzaque A, Ashraf A, et al. Prevalence of physical inactivity in nine rural INDEPTH health and demographic surveillance systems in five Asian countries. Glob Health Action. 2009;2:44-53.

20. Shetty P. Nutrition transition and its health outcomes. Indian J Pediatr. 2013;80(1):21-7, http://dx.doi.org/10.1007/ s12098-013-0971-5.

21. Moore MA. Diverse influences of dietary factors on cancer in Asia. Asian Pac J Cancer Prev. 2009;10(6):981-6.

22. Haby MM, Markwick A, Peeters A, Shaw J, Vos T. Future predictions of body mass index and overweight prevalence 
in Australia, 2005-2025. Health Promot Int. 2012;27(2): 250-60, http://dx.doi.org/10.1093/heapro/dar036.

23. World Health Organization. Obesity. WHO; 2012 [cited 2014 Mar 20]. Available from: http://www.wpro.who.int/ mediacentre/factsheets/obesity/en.

24. Aboobakur M, Latheef A, Mohamed AJ, Moosa S, Pandey RM, Krishnan A, et al. Surveillance for non-communicable disease risk factors in Maldives: Results from the first STEPS survey in Male. Int J Public Health. 2010;55(5): 489-96, http://dx.doi.org/10.1007/s00038-009-0114-y.

25. Lawes CM, Hoorn SV, Rodgers A. Global burden of bloodpressure-related disease, 2001. Lancet. 2008;371(9623): 1513-8, http://dx.doi.org/10.1016/S0140-6736(08)60655-8.

26. Arima H, Murakami Y, Lam TH, Kim HC, Ueshima H, Woo J, et al. Effects of prehypertension and hypertension subtype on cardiovascular disease in the Asia-Pacific Region. Hypertension. 2012;59(6):1118-23, http://dx.doi. org/10.1161/HYPERTENSIONAHA.111.187252.

27. Takahashi Y, Sasaki S, Okubo S, Hayashi M, Tsugane S. Blood pressure change in a free-living population-based dietary modification study in Japan. J Hypertens. 2006;24(3):451-8, http://dx.doi.org/10.1097/01.hjh.0000209980.36359.16.

28. Feigin VL, Krishnamurthi R. Stroke prevention in the developing world. Stroke. 2011;42(12):3655-8, http://dx.doi. org/10.1161/STROKEAHA.110.596858.

29. Shah P, Misra A, Gupta N, Hazra DK, Gupta R, Seth P, et al. Improvement in nutrition-related knowledge and behaviour of urban Asian Indian school children: Findings from the 'Medical education for children/Adolescents for Realistic prevention of obesity and diabetes and for healthy aGeing'(MARG) intervention study. Br J Nutr. 2010;104(03):427-36, http:// dx.doi.org/10.1017/S0007114510000681.

30. Eriksen M, Mackay J, Ross H. The tobacco atlas. Atlanta, GA: World Lung Foundation; 2012.

31. World Health Organization. WHO report on the global tobacco epidemic, 2013: Enforcing bans on tobacco advertising, promotion and sponsorship. Geneva: WHO; 2013.
32. Xu Y, Wu Q, Xu S, Xu J, Wan X, Guo Y. Environmental secondhand smoke exposure and policy assessment at five venues in Zhejiang Province, China. Asia Pac J Public Health. 2013;25(1):1-9.

33. Abidin EZ, Hashim Z, Semple S. Secondhand smoke in public spaces: How effective has partial smoke-free legislation been in Malaysia? Asian Pac J Cancer Prev. 2013;14(11): 6845-50, http://dx.doi.org/10.7314/APJCP.2013.14.11.6845.

34. Lim SH, Tai BC, Yuan J-M, Mimi CY, Koh W-P. Smoking cessation and mortality among middle-aged and elderly Chinese in Singapore: The Singapore Chinese health study. Tob Control. 2013;22(4):235-40, http://dx.doi.org/10.1136/ tobaccocontrol-2011-050106.

35. World Health Organization. Noncommunicable disease surveillance. Geneva: WHO; 2014 [cited 2014 Apr 1]. Available from: http://www.who.int/ncd_surveillance/en.

36. World Health Organization. STEPwise approach to chronic disease risk factor surveillance (STEPS). Geneva: WHO; 2014 [cited 2014 Mar 20]. Available from: http:// www.who.int/chp/steps/riskfactor/en.

37. World Health Organization. The STEPS instrument and support materials. Geneva: WHO; 2014 [cited 2014 Mar 6]. Available from: http:/www.who.int/chp/steps/instrument/en.

38. World Health Organization. STEPwise approach to surveillance (STEPS). Geneva: WHO; 2014 [cited 2014 Mar 12]. Available from: http://www.who.int/chp/steps/en.

39. World Health Organization. Intersectoral action on health: A path for policy-makers to implement effective and sustainable intersectoral action on health. First global ministerial conference on healthy lifestyles and noncommunicable disease control. Moscow: WHO; 2011.

40. World Health Organization. Strategy for the prevention and control of noncommunicable diseases. 28th Pan American Sanitary Conference; 2012 Sep 17-21; Washington, D.C., United States of America. Pan American Health Organization, WHO; 2012.

This work is available in Open Access model and licensed under a Creative Commons Attribution-NonCommercial 3.0 Poland License - http://creativecommons.org/ licenses/by-nc/3.0/pl/deed.en. 